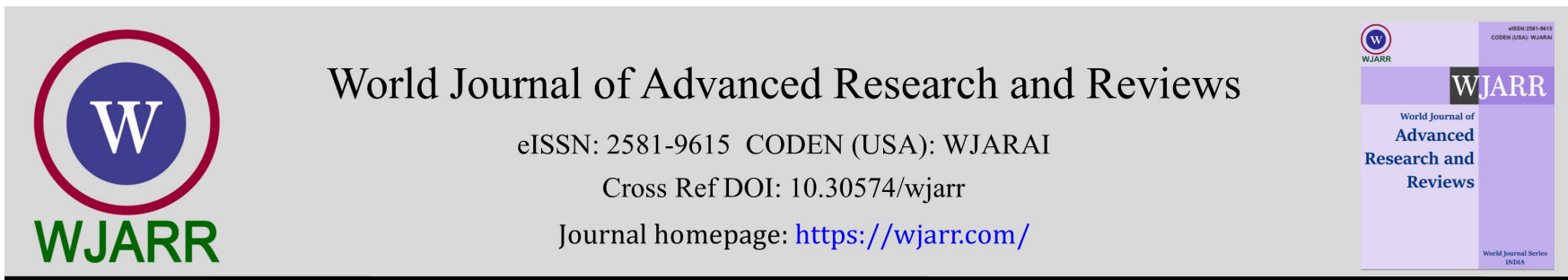

(RESEARCH ARTICLE)

\title{
Allelopathic activity of aqueous decomposed leaf litter extracts on the germination and early seedling growth of cowpea (Vigna unguiculata) in Aden, Yemen
}

\author{
Hana A. Al-Quhbi, Amna A.I. Saeed and Abdul Nasser Al-Gifri * \\ Biology Department Faculty of Education, University of Aden, Yemen.
}

World Journal of Advanced Research and Reviews, 2021, 10(02), 191-195

Publication history: Received on 06 April 2021; revised on 10 May 2021; accepted on 12 May 2021

Article DOI: https://doi.org/10.30574/wjarr.2021.10.2.0216

\begin{abstract}
Allelopathic effect of Aqueous decomposed leaf litter from four common trees and shrubs in Aden governorate, Yemen was investigated on the germination and early seedling growth of Cowpea, the test crop was subjected to four concentrations of $25,50,75$ and $100 \%$ of the aqueous extract, while a control was maintained at $0 \%$ extract level. The study carried out in the laboratory of Botany at Faculty of Education, University of Aden.

The Percentage of germination, Germination rate per plate, radicle length, plumule, (hypo and epicotyl lengths) observed. Data was recorded at 24 hours interval after germination for 15 days, the research revealed delayed germination rate per plate and a significant reduction in the radicle length and germination percentage (data was collected on percentage germination; plant height. Results obtained showed that significant reduction in the growth parameters considered at $100 \%$ and $75 \%$, while at $50 \%$ and $25 \%$ the difference was not significant.
\end{abstract}

From the result obtained, it can concluded that Conocarpus lancefolius and Thevetia peruviana possess allelopathic effect that inhibit the germination and early seedling growth of Cowpea, hence at $100 \%$ concentration.

\section{Keywords: Allelopathy; Azadirachta indcia; Pithecilubium dulce; Conocarpus lancefolius; Thevetia peruviana}

\section{Introduction}

Allelopathy is a biological phenomenon in which one or more biochemical produced influences the growth, survival, and reproduction of other organism. Plants species considered as rich source of secondary metabolites (allelochemicals), these chemicals modify the environmental system on other plants growing in their vicinity, and the phenomenon known as allelopathy [8]. The term allelochemicals derived from "Allelochmics" it was coined by [12]. Since then, the term used in literature dealing with interspecific chemical interaction between plants. In order, a compound to be designated as allelochemical its release into or its origin in the environment must be demonstrated [4]. These biochemicals known as allelochemicals and can have beneficial (Positive allelopathy) or detrimental (negative allelopathy) effect on the target organisms. $[12,14]$ explained that allelochemicals are a subset of secondary metabolites, which are not required for metabolism (i.e. growth, development and reproduction) of the allelopathic organism and the allelochemicals with negative allelopathic effect are an important part of the plant $[2,3]$.

Plants can favorably affect other plants through release into the environment of substances named allelochemicals [1]. A lot of study carried out on the effects of chemicals released by roots, leaves, fruits, and other parts of growing plants on the growth of another species [12]. Plants may influence the growth of each other by means of exudates, leachates from decomposing residues, and residues incorporated into growing medium. [10, 9]

\footnotetext{
${ }^{*}$ Corresponding author: AN Al-Gifri

Biology Dept. Faculty of Education, University of Aden, Yemen.

Copyright (C) 2021 Author(s) retain the copyright of this article. This article is published under the terms of the Creative Commons Attribution Liscense 4.0.
} 
Allelopathic studies in Yemen are rather very limited.

The goal of this study was to determine the possible allelopathic effects of commonly distributed plant in Aden and most of coastal part of the country (Conocarpus lancefolius, Pithecelibium dulce, Azadrichta indica and Thevetia peruviana.) " Figure (1): A, B, C, D" on germination and seedlings growth of Vigna uniguiculata (L.)Walp. Fabaceae.
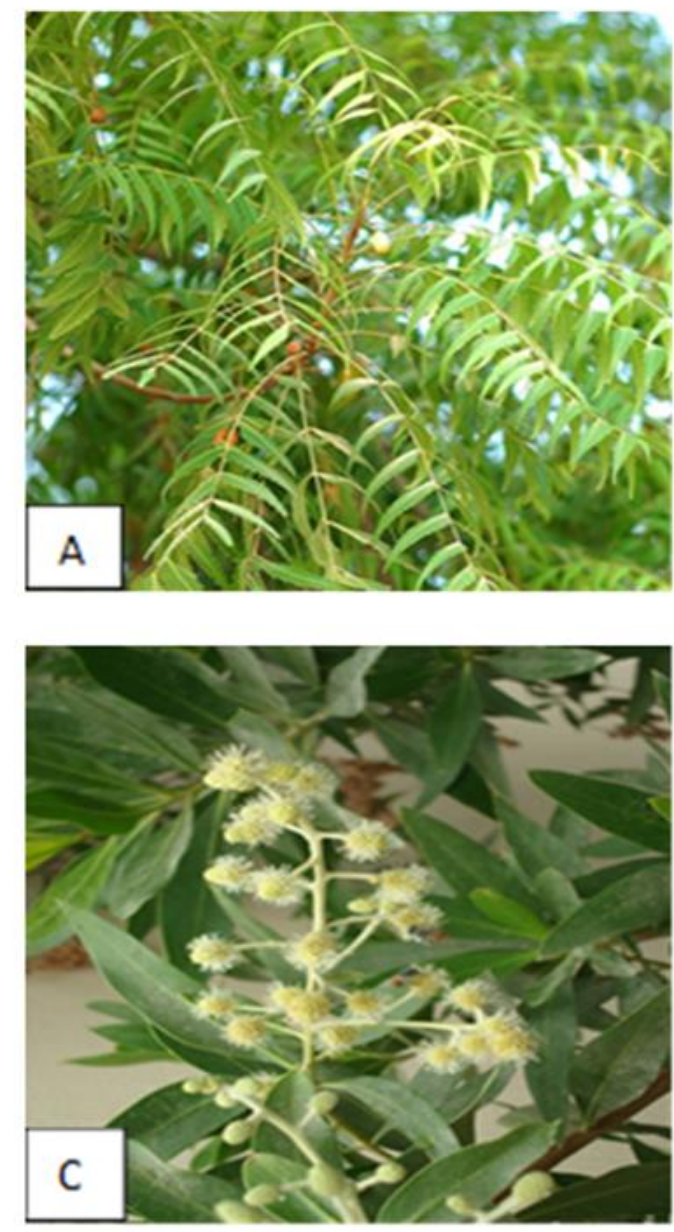
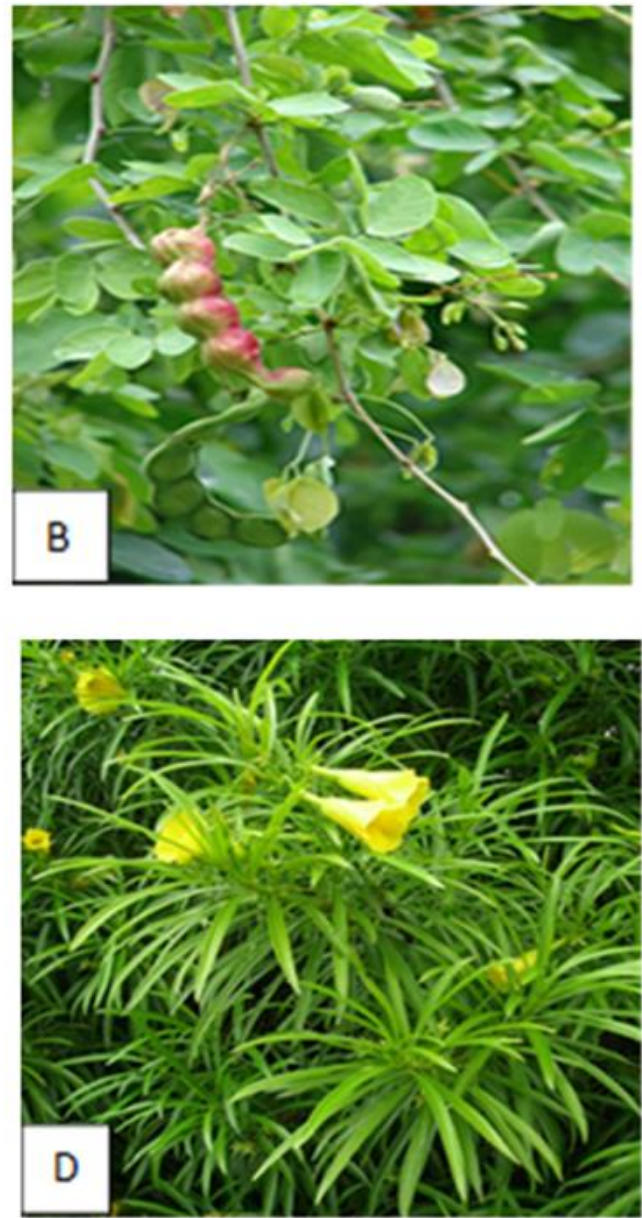

Figure 1 Common plants in Aden governorate, Yemen. A- Azadrichta indica, B- Pitheccilubium dulce, C- Conocarpus lancifolius, D- Thevetia peruviana

\section{Material and methods}

This research carried out in the laboratory of Biology Department, Faculty of Education, Aden University of Yemen. All the plant species used in this experiment grown in the Faculty campus. The Cowpea seeds purchased from the local market.

\subsection{Preparation of aqueous extract of the litter and soil}

The soil medium was mixed with distilled water at a ratio of 9:25 (w/v, which is equal to the ratio of $1 \mathrm{~g}$ of litter to 25 $\mathrm{ml}$ of water) and extracted by water for $24 \mathrm{~h}$. The soil and water mixtures then filtered. Five treatments viz, Control 1 treatment ( $0 \%$ extract), (25\% extract), (50\% extract), (75\% extract) and (100\% extract) were prepared to start the experiment. On 16 February 2020, at 10:30 am Aden time, start the Vigna unguiculata germination and seedling growth experiment to investigate the effects of the litter extracts on seed germination and seedling growth, on medical cottondish cultivation method used. 10 seeds in each plate with three replicates. The observation was at first $24 \mathrm{~h}$, for 14 days, the growth of radicals and plumules recorded daily. The average of three different growths Tallest (T), Medium (M) and Shortest (S), observed and recorded, for all the treatments and the replicates. 


\section{Results and discussion}

The results summarized in the tables (1-6)

While analysis the result the following findings observed:

- The percentage of the germination at $25 \%$ extract was higher with Pithiceliubum dulce (78\%) and Azadrichta indica $(71.6 \%)$. (Table 1$)$.

- At 50\% extract, the Conocarpus lancefolius with (79.6\%) and Thevetia peruviana with (46\%). (Table 1 )

- The Vigna radical and plumule growth comparing to control

- At $25 \%$ of Thevetia peruviana, Pithiceliubum dulce and Conocarpus lancefolius were taller than the control. (Table 2,4,5,6).

- Azadrichta indica was shorter than the control except the epicotyl growth was higher. (Table 2,4,5,6).

- At $100 \%$ was the fatal for all except Pithiceliubum dulce with (11\%) and Azadrichta indica with (6.6\%). (Table $2,3,4)$.

Table 1 Effect of Plant Extracts on the Germination Percentage of Cowpea

\begin{tabular}{|l|l|l|l|l|l|l|}
\hline Treatment & Con \% & Control & Azad. & Pith & Cono & Thev. \\
\hline \multirow{2}{*}{$\begin{array}{l}\text { Vigna unguiculata } \\
\text { with Soil } \\
\text { decomposed } \\
\text { leaf extract }\end{array}$} & 0 & 100 & 0 & 0 & 0 & 0 \\
\cline { 2 - 8 } & 25 & 0 & 71.6 & 78 & 55.3 & 41.3 \\
\cline { 2 - 7 } & 50 & 0 & 47.6 & 58.6 & 79.6 & 46 \\
\cline { 2 - 7 } & 75 & 0 & 37.6 & 16.6 & 39.6 & 29.3 \\
\cline { 2 - 7 } & 100 & 0 & 6.6 & 11 & 0 & 0 \\
\hline
\end{tabular}

Table 2 The effect of control on radical/plumule growth in $\mathrm{cm}$

\begin{tabular}{|l|l|l|l|l|l|l|l|l|l|l|}
\hline \multirow{2}{*}{ Treatment } & \multirow{2}{*}{ Con.\% } & \multicolumn{4}{|l|}{ Radical } & \multicolumn{3}{l|}{ hypocotyl } & \multicolumn{3}{|l|}{ epicotyl } \\
\cline { 3 - 10 } & & T & M & S & T & M & S & T & M & S \\
\hline $\begin{array}{l}\text { Vigna unguiculata } \\
\text { seeds with water only }\end{array}$ & 0 & 7 & 5 & 4 & 10 & 8.5 & 6 & 5.5 & 2.7 & 1.7 \\
\hline
\end{tabular}

Table 3 The effect of Azadaricta indica extract on radical/ plumule growth in $\mathrm{cm}$

\begin{tabular}{|l|l|l|l|l|l|l|l|l|l|l|}
\hline \multirow{2}{*}{ Treatment } & \multirow{2}{*}{ Con.\% } & \multicolumn{4}{|l|}{ Radical } & \multicolumn{2}{l|}{ Hypocotyl } & \multicolumn{2}{l|}{ Epicotyl } \\
\cline { 2 - 12 } & & T & M & S & T & M & S & T & M & S \\
\hline \multirow{2}{*}{$\begin{array}{l}\text { Vigna unguiculata } \\
\text { seeds with Soil and }\end{array}$} & 25 & 4.5 & 3.6 & 3.3 & 8.5 & 6.7 & 5 & 9 & 6 & 4 \\
\cline { 2 - 12 } $\begin{array}{l}\text { Decomposed leaf } \\
\text { extract }\end{array}$ & 50 & 2.5 & 3 & 3 & 6 & 5.7 & 4 & 1.5 & 1.2 & 1 \\
\cline { 2 - 11 } & 75 & 2.5 & 1.5 & 1 & 5 & 4.5 & 1.7 & 5 & 3 & 1.3 \\
\cline { 2 - 11 } & 100 & 1 & 0.5 & 0.5 & 3 & 2.7 & 1 & 0.8 & 0.6 & 1 \\
\hline
\end{tabular}


Table 4 The effect of Pithiceliubum dulce extract on radical/ plumule growth in $\mathrm{cm}$

\begin{tabular}{|c|c|c|c|c|c|c|c|c|c|c|}
\hline \multirow[t]{2}{*}{ Treatment } & \multirow[t]{2}{*}{ Con.\% } & \multicolumn{3}{|c|}{ Radical } & \multicolumn{3}{|c|}{ Hypocotyl } & \multicolumn{3}{|c|}{ Epicotyl } \\
\hline & & $\mathbf{T}$ & $\mathbf{M}$ & $S$ & $\mathbf{T}$ & $\mathbf{M}$ & $S$ & $\mathbf{T}$ & $\mathbf{M}$ & $S$ \\
\hline \multirow{4}{*}{$\begin{array}{l}\text { Vigna } \\
\text { unguiculata } \\
\text { seeds with Soil } \\
\text { and } \\
\text { Decomposed leaf } \\
\text { extract }\end{array}$} & 25 & 8.2 & 5 & 3.5 & 11.3 & 8 & 7 & 8.4 & 6 & 3 \\
\hline & 50 & 4.5 & 3.8 & 3 & 7 & 7.3 & 3 & 5.5 & 3 & 1 \\
\hline & 75 & 5 & 3 & 2.5 & 6.5 & 6 & 5.3 & 4.5 & 3.5 & 1.2 \\
\hline & 100 & 1.2 & 0.9 & 0.3 & 2.8 & 1.8 & 2 & 1.2 & 1.2 & 0.5 \\
\hline
\end{tabular}

Table 5 The effect of Conocarpus lancefolius extract on radical/plumule growth in $\mathrm{cm}$

\begin{tabular}{|c|c|c|c|c|c|c|c|c|c|c|}
\hline \multirow[t]{2}{*}{ Treatment } & \multirow[t]{2}{*}{ Con.\% } & \multicolumn{3}{|c|}{ Radical } & \multicolumn{3}{|c|}{ Hypocotyl } & \multicolumn{3}{|c|}{ Epicotyl } \\
\hline & & $T$ & $\mathbf{M}$ & $S$ & $\mathbf{T}$ & $\mathbf{M}$ & $S$ & $\mathrm{~T}$ & $\mathbf{M}$ & $S$ \\
\hline \multirow{4}{*}{$\begin{array}{l}\text { Vigna } \\
\text { unguiculata } \\
\text { seeds with Soil } \\
\text { and } \\
\text { Decomposed leaf } \\
\text { extract }\end{array}$} & 25 & 7 & 6.5 & 4 & 10.5 & 9 & 7 & 9.5 & 5 & 1 \\
\hline & 50 & 4 & 3.8 & 3.5 & 8.5 & 6.7 & 5 & 8.2 & 5.7 & 4.3 \\
\hline & 75 & 5 & 3 & 2.5 & 6.5 & 6 & 5.3 & 5.5 & 3.5 & 1.2 \\
\hline & 100 & 0 & 0 & 0 & 0 & 0 & 0 & 0 & 0 & 0 \\
\hline
\end{tabular}

Table 6 The effect of Thevetia peruviana extract on radical/ plumule growth in $\mathrm{cm}$

\begin{tabular}{|l|l|l|l|l|l|l|l|l|l|l|}
\hline \multirow{2}{*}{ Treatment } & \multirow{2}{*}{ Con.\% } & \multicolumn{4}{|l|}{ Radical } & \multicolumn{3}{l|}{ Hypocotyl } & \multicolumn{2}{l|}{ Epicotyl } \\
\cline { 2 - 13 } & & $\mathbf{T}$ & $\mathbf{M}$ & $\mathbf{S}$ & $\mathbf{T}$ & $\mathbf{M}$ & $\mathbf{S}$ & $\mathbf{T}$ & $\mathbf{M}$ & $\mathbf{S}$ \\
\hline \multirow{2}{*}{$\begin{array}{l}\text { Vigna unguiculata } \\
\text { seeds with Soil and } \\
\begin{array}{l}\text { Decomposed leaf } \\
\text { extract }\end{array}\end{array}$} & 25 & 9.5 & 7.2 & 3.5 & 12 & 6 & 5.5 & 8 & 4 & 3 \\
\cline { 2 - 13 } & 50 & 4 & 3 & 4.2 & 7 & 3.5 & 2 & 3.5 & 1.5 & 0.8 \\
\cline { 2 - 12 } & 100 & 0 & 0 & 0 & 0 & 0 & 0 & 0 & 0 & 0 \\
\hline
\end{tabular}

The results obtained in the present study corroborates with the results obtained from similarly several studies have proved the allelopathic efficacy of several species have on seed germination and seedling growth $[1,5,6,8,10]$ Indeed, the radicle growth was more sensitive to allelochemicals than the plumule growth. The results obtained in the present study are in agreement with many previous research studies on allelopathy. [7, 9, 11, 13].

\section{Conclusion}

It can be concluded that aqueous leaf extract of common trees and shrubs in Aden, inhibit delays or suppress the germination and early seedling growth of cowpea, even though at lower concentrations it tends to stimulate the germination and growth of the test plant, hence, have the potential to be used as an alternative to synthetic herbicide.

\section{Recommendations}

It recommended that further research should carried out to investigate the effect of those plants, on the germination of different crop in the study area. It further recommended that farmers should take appropriate care on some of the plant that may cause damage to their crops on the farms during land preparation. 


\section{Compliance with ethical standards}

\section{Acknowledgments}

We thank the Department of Biology, Faculty of Education for providing necessary laboratory facilities to carry out this work.

\section{Disclosure of conflict of interest}

Hana A. Al-Quhbi, Amna A.I. Saeed and Abdul Nasser Al-Gifri, declare that there was no conflict of interest.

\section{References}

[1] Czarnota MA, Paul RN, Danyan FE, Nime C1, West T. Localization of production, Chemical composition and mode of action of Sorgoleone Weed Technology. 2007; 813-825.

[2] Duke So, Lydon J. Natural phytotoxins on herbicides in Duke, S.O. Men, J. J. and PI immer, J. R (Ed.) Pest control with enhanced environmental safety. American Chemical Society. Washington DC. 1993.111-121 pp.

[3] Duke SO, Dayan FE, Hernandez A, Duke MV, Abbas HK. Natural products as leads for new herbicide mode of action. In the 2002 Brighton Crop Protection Conference- Weeds. 2002; 578-586.

[4] Eihellig FA. Allelopathy: status and future Goals. In Allelopathy.Organisms processes and applications. (Ed Inderjit, K. M MDakshini and Einhellig), pp 1-24 American Chemical Society. 1995; 45-48.

[5] Kaushal R, Verma KS, Singh KN. Allelopathic effect of Morusalba and Toonaciliata on ermination and seedling growth of field crops. Ind. J. Forestry. 2006; 29(4): 385-388.

[6] Khan M, Hussain F, Musharaf S. Allelopathic potential of Rhazya stricta Decne on germination of Pennisetum typhoides. International Journal of Biosciences (IJB). 2011; 1(4): 80-85.

[7] Musa DD, Aliero AA, Bashir KA. Preliminary Allelopathic Activity of Aqueous Leaf Extract of Senna Occidentalis on the Germination and Early Seedling Growth of Cowpea (Vigna Unguiculata). International Journal of Current Science and Studies (IJCSS). 2017; 1(1): 23-25.

[8] Nandal DPS, Birla SS, Narwal SS, Koushik JC. Allelopathic interactions in agroforestry systems. In Allelopathy in agriculture and forestry. Jodhapur: Scientific Publishers. 1994; 93-130.

[9] Popoola KM, Akinwale RO, Adelusi AA. Allelopathic effect of extracts from selected weeds on germination and seedling growth of cowpea (Vigna unguiculata (L.) Walp. Varieties. Afr. J. Plant Sci. 2020; 14(9): 338-349.

[10] Pravin Rawat SS, Narkhede AD, Rane VM, Mhaiske, VV Dalvi. Allelopathic effect of solid bamboo (Dendrocalamus stocksii Munro) on Cowpea (Vigna unguiculata), Indian Forester. 2018; 144(3): 238-242.

[11] Price AJ, Stoll ME, Bergtold JS, Arriaga FJ, Balkcom KS, Kornecki TS, Raper RL.Effect of cover crop extracts on cotton and radish radicle elongation. Communications in Biometry and Crop Science. 2008; 3: 60-66.

[12] Rice E, Elroy L. Allelophaty. Sandiego, CA: Academic Press. 1st ed., 1974: 1-399 pp.

[13] Smitha Parayangattil Subramanian, Sona Peter. Allelopathic potential of selected weed plants on seed germination of Cowpea (Vigna unguicilata).International Award Conference on Multidisciplinary Innovation, Bali, Indonesia. 2019; 46-57.

[14] Willis RJ. The history of allelopathy. Springer Science and Business Media; 2007 :1-299 pp. 